\title{
Co-firing Coal: Feedlot and Litter Biomass Fuels
}

\section{Quarterly Progress Report no: 3}

Grant \#:

Project Name :

\author{
DE-FG26-00NT40810
}

Feedlot and Litter Biomass Co-firing in Pulverized Fuel and Fixed

Bed Burners

Contractor name: Texas Engineering Experiment Station, Texas A\&M University

Sponsor:

Principal Investigator: Dr. Kalyan Annamalai, Mech.Engg, Texas A\&M, College Station,

TX 77843-3123

979-845-2562

Kannamalai@mengr.tamu.edu

Other Investigators: Dr. John Sweeten, Professor of Agricultural Eng. and Resident Director of Agricultural Extension Service,

Dr. Sayeed Mukhtar, Asst. Prof., Agricultural Engineering.

Graduate Students: Ben Thien $(\mathrm{PhD})$

Gengsheng Wei (PhD)

Soyuz Priyadarsan (MS)

Quarterly Report \#: 3

Report Period: $\quad$ 12/15/00-3/14/2001 


\section{PROGRESS}

\section{Proposed activities for quarter $3(12 / 15 / 00-3 / 14 / 01)$}

1. Conduct TGA and fuel characterization studies - Task 1.

2. Continue to perform re-burn experiments. - Task 2

3. Design fixed bed combustor. - Task 3.

4. Modify the PCGC2 code to include moisture evaporation model - Task 4.

\section{A. Achieved During Quarter 3 (12/15/0-3/14/01)}

1. Conducted TGA and Fuel Characterization studies (Appendix I). A comparison of fuel properties, TGA traces etc is given in Appendix I. Litter has 3 and 6 times more $\mathrm{N}$ compared to coal on mass and heat basis. The $\mathrm{P}$ of litter is almost $2 \%$ ! (Task 1 ). Both litter biomass (LB) and feedlot biomass (FB) have been pulverized. The size distributions are similar for both litter and FB in that $75 \%$ pass through $150 \mu \mathrm{m}$ sieve while for coal75 \% pass through $60 \mu \mathrm{m}$ sieve. Rosin Rammler curve parameters are given. The TGA characteristics of FB and LB are similar and pyrolysis starts at $100 \mathrm{C}$ below that of coal.

2. Reburn experiments with litter and with FB have been performed (Appendix II) Task 2. Litter is almost twice effective (almost 70-90 \% reduction) compared to coal in reducing the $\mathrm{NOx}$ possibly due to presence of $\mathrm{N}$ in the form of $\mathrm{NH}_{3}$.

3. Designed fixed bed gasifier/combustor (Appendix III) - Task 3

4. Modified PCGC2 to include moisture evaporation model in coal and biomass particles. (Appendix IV) - Task 4

\section{Proposed activities for quarter 4 (3/15/0-6/14/01)}

1. Conduct ignition temperature analysis, including the effects of varying the amount of char in Lb and FB. - Task 1.

2. Conduct boiler burner co-firing experiments with coal and litter - Task 2

3. Fabricate the fixed bed gasifier/combustor - Task 3.

4. Modify PCGC2 to account for reactions of of phosphorous with $\mathrm{NH} 3$ and predict PO2 and P2O5 emissions. - Task 4 


\section{Appendix I: Fuel Characterization}

If feedlot or litter biomass is to be used in pulverized coal boiler burners, the fuel properties must first be analyzed. Here the ultimate, proximate, size parameters and kinetic parameters will be presented. The basic fuel properties for coal, feedlot biomass, litter biomass, and 90-10 biomass fuel blends are shown in table 1. The analysis shows that feedlot biomass and litter biomass both have a higher ash content, a lower moisture content, and a lower heating value than coal. The biomass is relatively low in fixed carbon compared to coal, and if taken on a dry ash free basis, the biomass will have a higher volatile content. Additionally, the biomass has a higher nitrogen, sulfur, and chlorine content. The higher nitrogen and sulfur content can present problems when biomass is used as a fuel, because these elements can combine with oxygen to form $\mathrm{SO}_{2}$ and $\mathrm{NO}_{\mathrm{x}}$, which are recognized air pollutants. The chlorine presents an additional problem in pulverized coal combustion, as any chlorine present in ash will accelerate boiler water tube corrosion. Chicken litter also has high phosphorus content, which presents addition problems. By examining the fuel properties, it is seen that biomass is not as high a quality fuel as coal and biomass and litter biomass have similar properties.

In addition to the ultimate and Proximate analysis, the different fuel were also size classified with a sieve shaker according to ASME specifications, and fit to the RosinRammler size classification. The Rosin-Rammler size distribution is shown below as:

$$
D=100\left(1-e^{-b x^{n}}\right)
$$

Where: $\quad \mathrm{D}=$ Percentage of particles having size $<\mathrm{x}$

$$
\begin{aligned}
& \mathrm{x}=\text { Particle Diameter } \\
& \mathrm{b}=\text { Constant, measure of spread } \\
& \mathrm{n}=\text { Constant, characteristic of substance } \\
& \mathrm{x}=\text { Particle diameter }
\end{aligned}
$$

or

$$
R=100-D=100 e^{-b x^{m}}
$$

Where: $\quad R=$ Percentage of particles having size $>\mathrm{x}$

The results of the Rosin Rammler are shown in figure 1, with the constants presented in table 2. The results show that the coal is ground more finely than either type of biomass. This is due to the inclusion of particles in the biomass that are compressed during the grinding the process instead of being broken up. The results also show again, the 2 types of biomass are very similar.

The kinetic parameters were obtained through the use of Thermogravimetric Analysis (TGA). The samples were analyzed in nitrogen and air to obtain time/temperature traces. The coal, litter and a 90:10 blend were analyzed in 4 size groups: $<45 \mu \mathrm{m}, 45-75 \mu \mathrm{m},>75 \mu \mathrm{m}$, and a full size distribution. A typical litter TGA trace is shown in figure 3 . Notice that the litter begins to pyrolyze at a lower temperature 
than coal, and releases volatiles more rapidly. The coal and the litter sample were both fitted with the parallel reaction model to determine an average activation energy, and standard deviation of activation energies. Assume the process is described by a series $i^{\text {th }}$ of first order reactions:

$$
\frac{d V_{i}}{d t}=\left(V_{i}^{*}-V_{i}\right) k o_{i} \exp \left(-\frac{E_{i}}{R T}\right)
$$

Where: $\quad \mathrm{V}=$ Mass of volatiles released $(\mathrm{kg})$

$\mathrm{V}^{*}=$ Maximum volatile content $(\mathrm{kg})$

$\left(\mathrm{V}^{*}-\mathrm{V}\right)=$ Mass of volatiles remaining $(\mathrm{kg})$

$\mathrm{t}=$ Time $(\min )$

ko $=$ Preexponential factor $(1 / \mathrm{min})$

$\mathrm{E}=$ Activation Energy $(\mathrm{kJ} / \mathrm{kmol}-\mathrm{K})$

$\mathrm{T}=$ Temperature $(\mathrm{K})$

Integrating equation 2:

$$
V_{i}^{*}-V_{i}=V_{i}^{*} \exp \left(-\int_{0}^{t} k o_{i} \exp \left(-\frac{E_{i}}{R T}\right) d t\right)
$$

Now it is assumed that the distribution of reactions is continuous and described by the function $\mathrm{f}(\mathrm{E})$ such that:

$$
\begin{aligned}
& d V^{*}=V^{*} d F=V^{*} f(E) d E \\
& \int_{-\infty}^{\infty} f(E) d E=1 \\
& f(E)=\frac{1}{\sqrt{2 \pi}} \exp \left(-\frac{(E-E m)^{2}}{2 \sigma^{2}}\right)
\end{aligned}
$$

Assume that $\mathrm{ko}_{\mathrm{i}}=\mathrm{ko}$, multiply eq (3) by $\mathrm{f}(\mathrm{E}) \mathrm{dE}$ and integrate over all activation energies:

$$
V^{*}-V=V^{*} \int_{-\infty}^{\infty} \exp \left(-\int_{0}^{t} k o \exp \left(-\frac{E}{R T}\right) d t\right) f(E) d E
$$

If the distribution $\mathrm{f}(\mathrm{E})$ is chosen to the a Gaussian distribution described by an average $\mathrm{E}$ and standard deviation $(\sigma)$, and the heating rate $\beta=\mathrm{dT} / \mathrm{dt}$ is substituted, the following is obtained:

$$
V^{*}-V=\frac{V^{*}}{\sigma(2 \pi)^{1 / 2}} \int_{E m-3 \sigma}^{E m+3 \sigma} \exp \left(-\frac{k o}{\beta} \int_{T o}^{T} \exp \left(-\frac{E}{R T}\right) d T-\frac{\left(E-E_{m}\right)^{2}}{2 \sigma^{2}}\right) d E
$$


The limits on the outside integral have been changed to facilitate integration. The limits of \pm 3 sigma include $99 \%$ of the activation energies.

Where: $\quad \mathrm{E}_{\mathrm{m}}=$ Average activation energy $(\mathrm{kJ} / \mathrm{kmol}-\mathrm{K})$

$\beta=$ Heating rate $(\mathrm{K} / \mathrm{min})$

$\sigma=$ Standard deviation of activation energies $(\mathrm{kJ} / \mathrm{kmol}-\mathrm{K})$

$\mathrm{T}=$ Temperature $(\mathrm{K})$

$\mathrm{T}_{\mathrm{o}}=$ Initial Temperature $(\mathrm{K})$

The TGA traces were curve fit to the parallel reaction model through the use of numerical integration and the minimization of the squared error. A value of $1.002 \times 10^{15}$ $1 /$ min was chosen as the value of $k_{0}$. A graph showing a curve fit to the full size group of litter is shown in figure 3 . The model parameters are presented in table 3 , and figures 5 and 6 present the results graphically. The results show that litter biomasses will generally have lower average activation energy than coal. Litter biomass will release volatiles faster, and at a lower temperature than coal. The behavior of the blend is dominated by the behavior of the coal. This result is not surprising, as the blend is $90 \%$ coal by mass. 


\section{Appendix I Figure and Tables}

Table 1: Fuel ultimate and proximate analysis

\begin{tabular}{|l|l|l|l|l|l|}
\hline & Coal & Feedlot & Litter & Feedlot 90-10 & Litter 90-10 \\
\hline \hline $\mathrm{C}$ & 60.3 & 23.6 & 28.4 & 56.6 & 57.11 \\
\hline $\mathrm{H}$ & 3.62 & 2.9 & 3.7 & 3.55 & 3.63 \\
\hline $\mathrm{O}$ & 14.5 & 19.1 & 22.8 & 15.0 & 15.33 \\
\hline $\mathrm{N}$ & 0.96 & 1.78 & 3.04 & 1.04 & 1.17 \\
\hline $\mathrm{S}$ & 0.23 & 0.5 & 0.66 & 0.26 & 0.27 \\
\hline $\mathrm{Cl}$ & $<.1$ & 1.85 & 0.93 & $\mathrm{NA}$ & $\mathrm{NA}$ \\
\hline $\mathrm{DL}$ & 15.12 & 7.7 & 11.6 & 14.4 & 14.8 \\
\hline $\mathrm{FC}$ & 42.38 & 6.5 & 22.5 & 38.8 & 40.40 \\
\hline $\mathrm{VM}$ & 37.17 & 41.4 & 50.7 & 37.6 & 38.52 \\
\hline Ash & 5.33 & 44.2 & 26.8 & 9.21 & 7.48 \\
\hline $\begin{array}{l}\mathrm{HHV} \\
\mathrm{kJ} / \mathrm{kg})\end{array}$ & 23709.8 & 9423 & 12066 & 22281 & 22545 \\
\hline $\mathrm{P}$ & $\mathrm{NA}$ & $\mathrm{NA}$ & 1.965 & $\mathrm{NA}$ & $\mathrm{NA}$ \\
\hline $\mathrm{T}_{\text {adiabatic }}$ & $2178 \mathrm{~K}$ & $1868 \mathrm{~K}$ & $1869 \mathrm{~K}$ & $2167 \mathrm{~K}$ & $2160 \mathrm{~K}$ \\
\hline $\mathrm{A}: \mathrm{F}_{\text {stoich }}$ & 8.14 & 3.68 & 4.66 & 7.70 & 7.80 \\
\hline
\end{tabular}




\section{Particle Size Distribution of Coal and Biomass (Ground at Vortek, CA)}

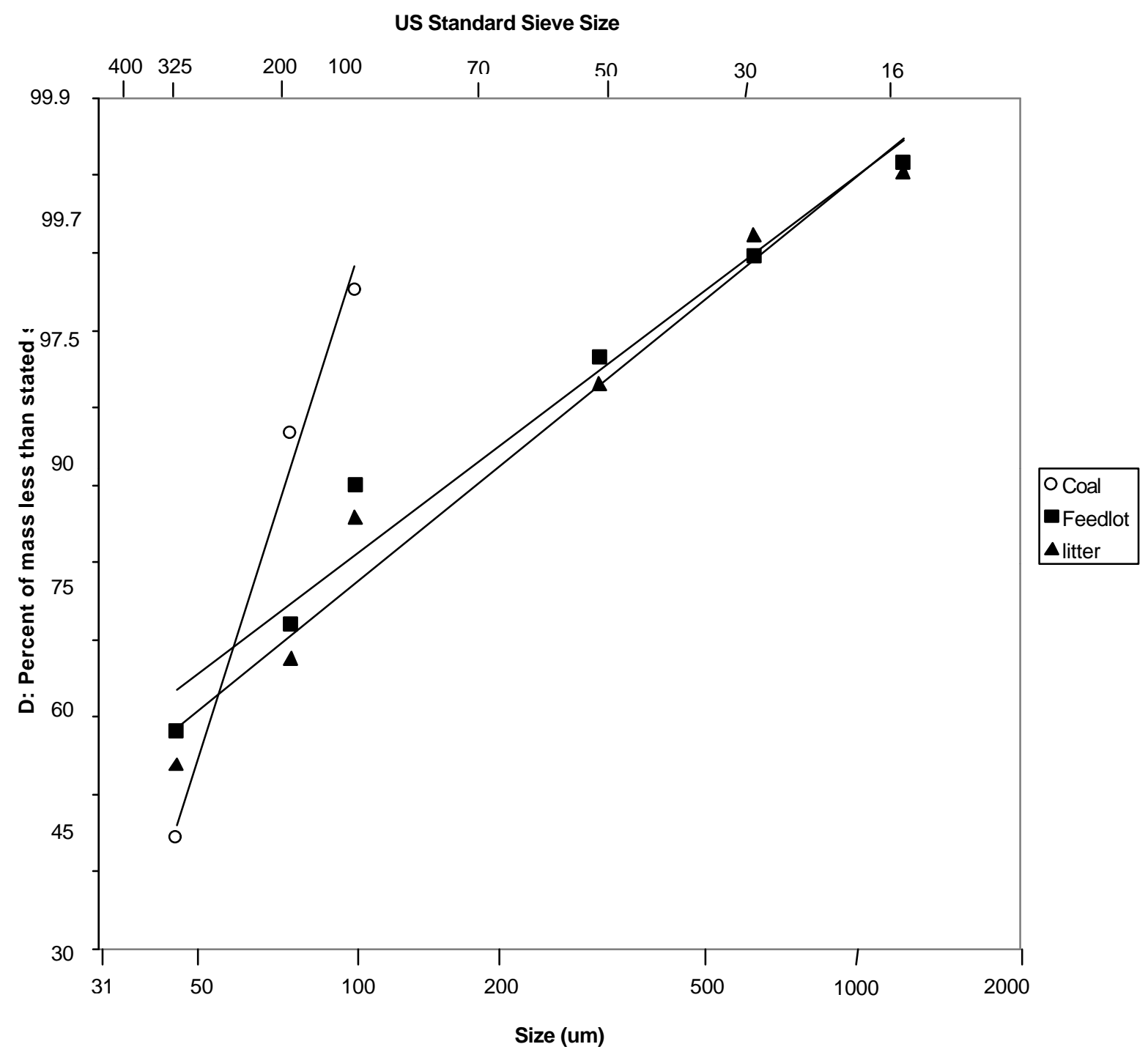

Figure 1: Rosin-Rammler size distribution of coal and biomass

Table 2: Rosin-Rammler Parameters

\begin{tabular}{|l|l|l|}
\hline Fuel & $\mathrm{n}$ & $\mathrm{b}$ \\
\hline Coal & 4.1559 & $1.637 \mathrm{E}-6$ \\
\hline Feedlot Biomass & 1.0007 & .00601 \\
\hline Litter Biomass & 1.0751 & .00361 \\
\hline
\end{tabular}




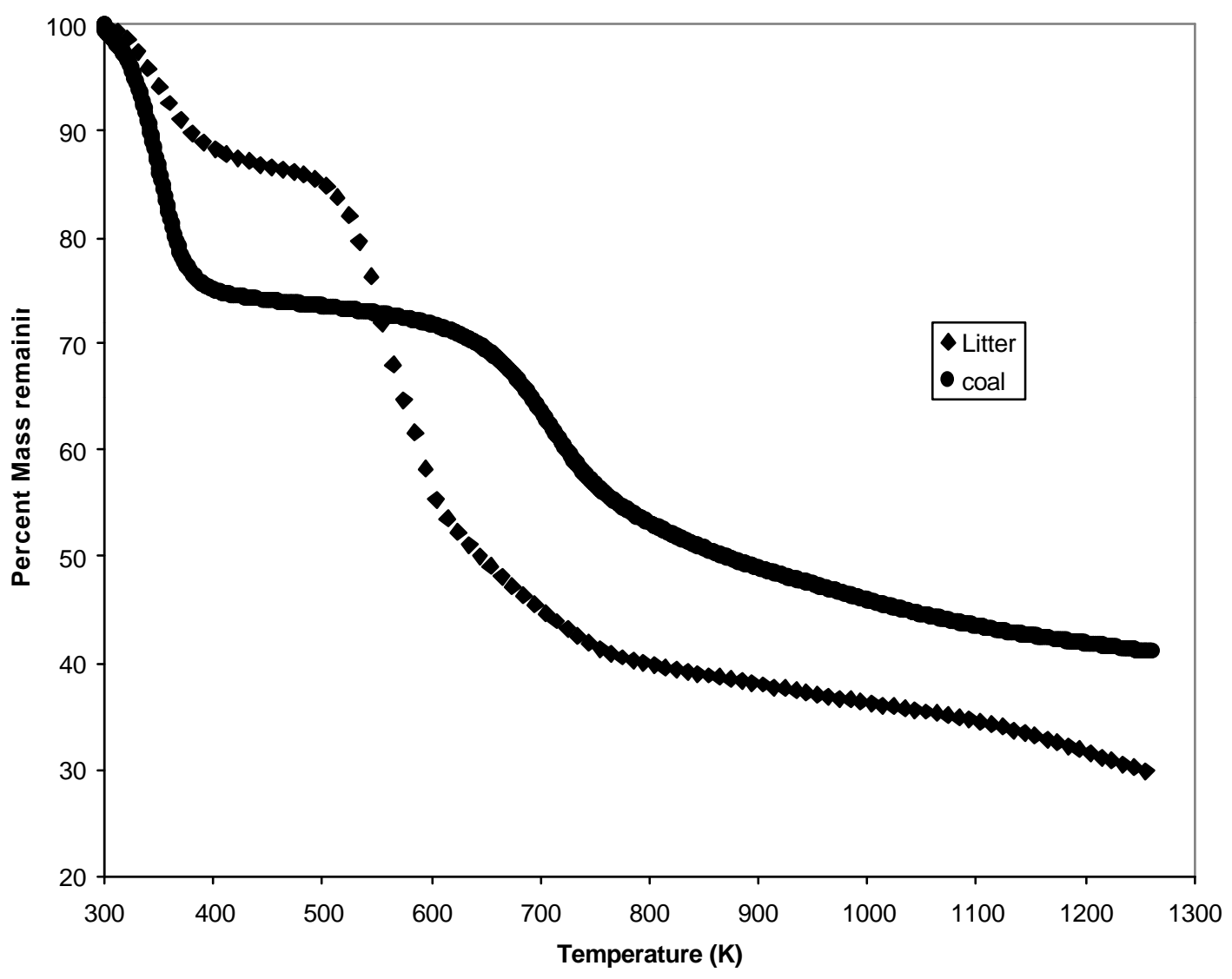

Figure 3: $\quad$ TGA trace of coal and litter biomass. 


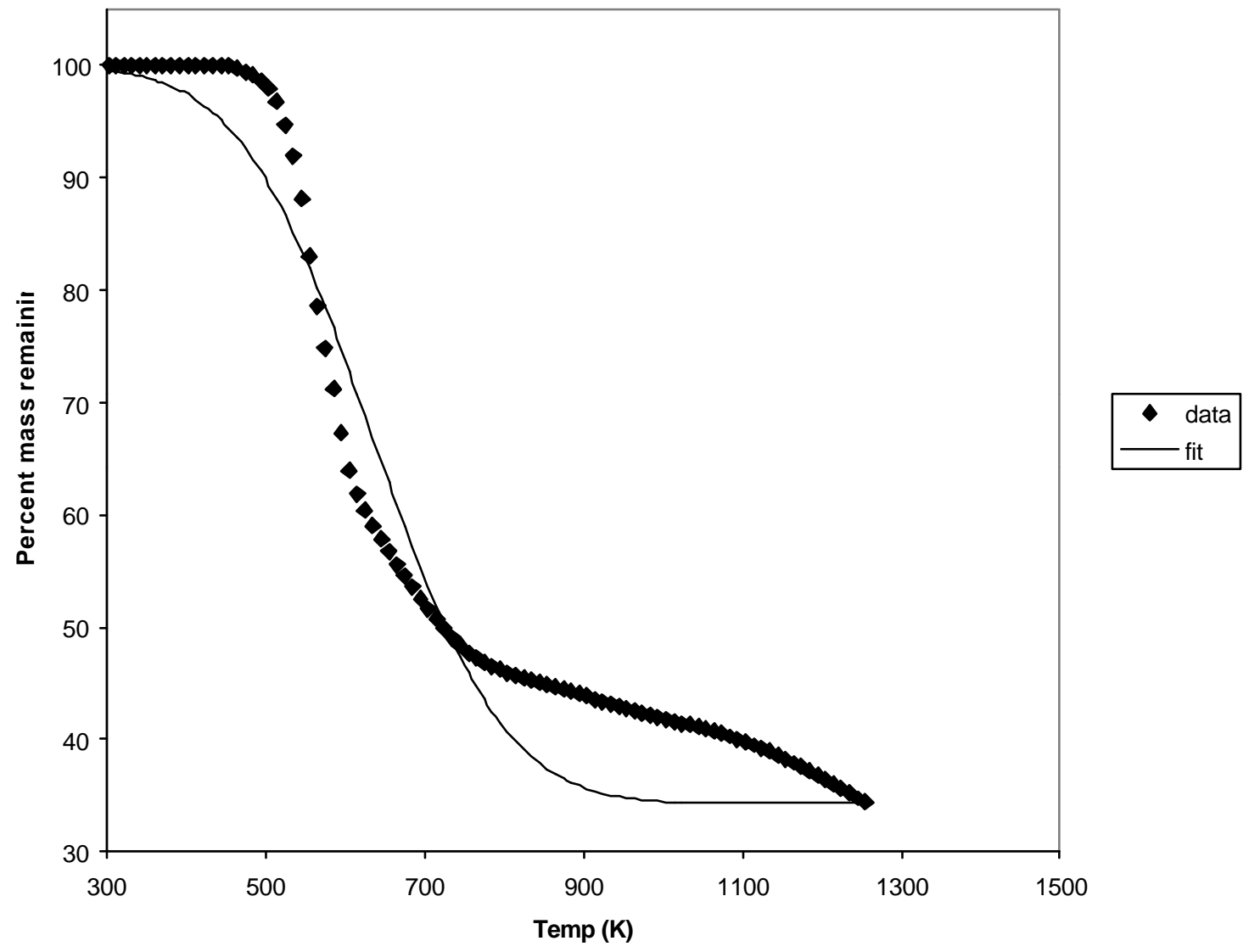

Figure 4: Full size group of litter fit to the parallel reaction model 


\begin{tabular}{|l|l|l|l|}
\hline E $(\mathrm{kJ} / \mathrm{kmol})$ & & & \\
\hline & Coal & Litter & $90: 10$ \\
\hline full & 232200 & 187700 & 222600 \\
\hline $75+$ & 264000 & 185100 & 215000 \\
\hline $45-75$ & 231000 & 193900 & 226300 \\
\hline $45-$ & 234300 & 199900 & 231100 \\
\hline sigma & & & \\
\hline \hline & Coal & Litter & $90: 10$ \\
\hline full & 48100 & 39300 & 47500 \\
\hline $75+$ & 51000 & 35400 & 47600 \\
\hline $45-75$ & 47200 & 47000 & 49500 \\
\hline $45-$ & 51000 & 53300 & 53900 \\
\hline
\end{tabular}

Table 3: Values of $\mathrm{E}_{\mathrm{m}}$ and Sigma for coal and litter biomass. 


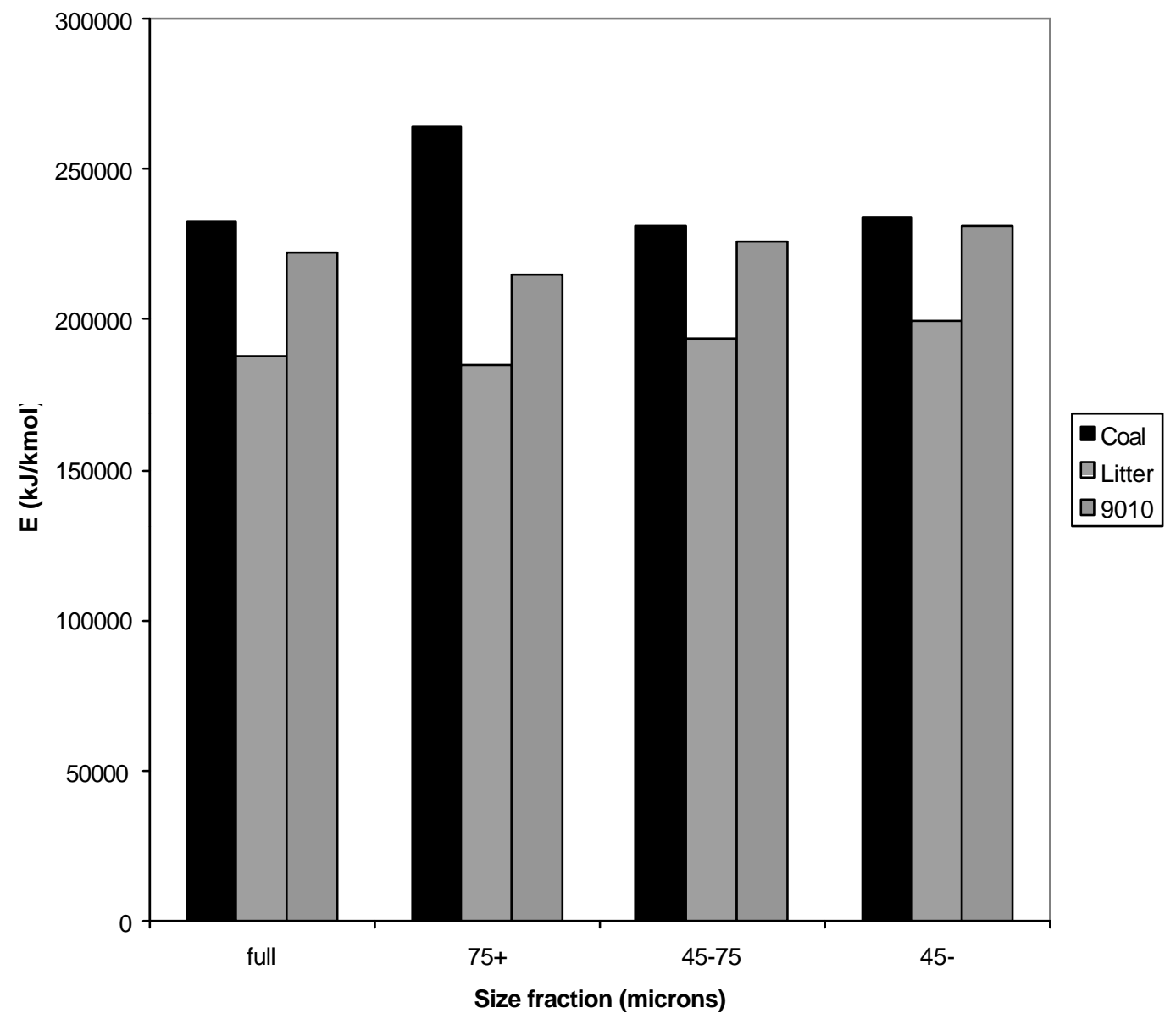

Figure 5: $\mathrm{E}_{\mathrm{m}}$ values for blend litter and coal 


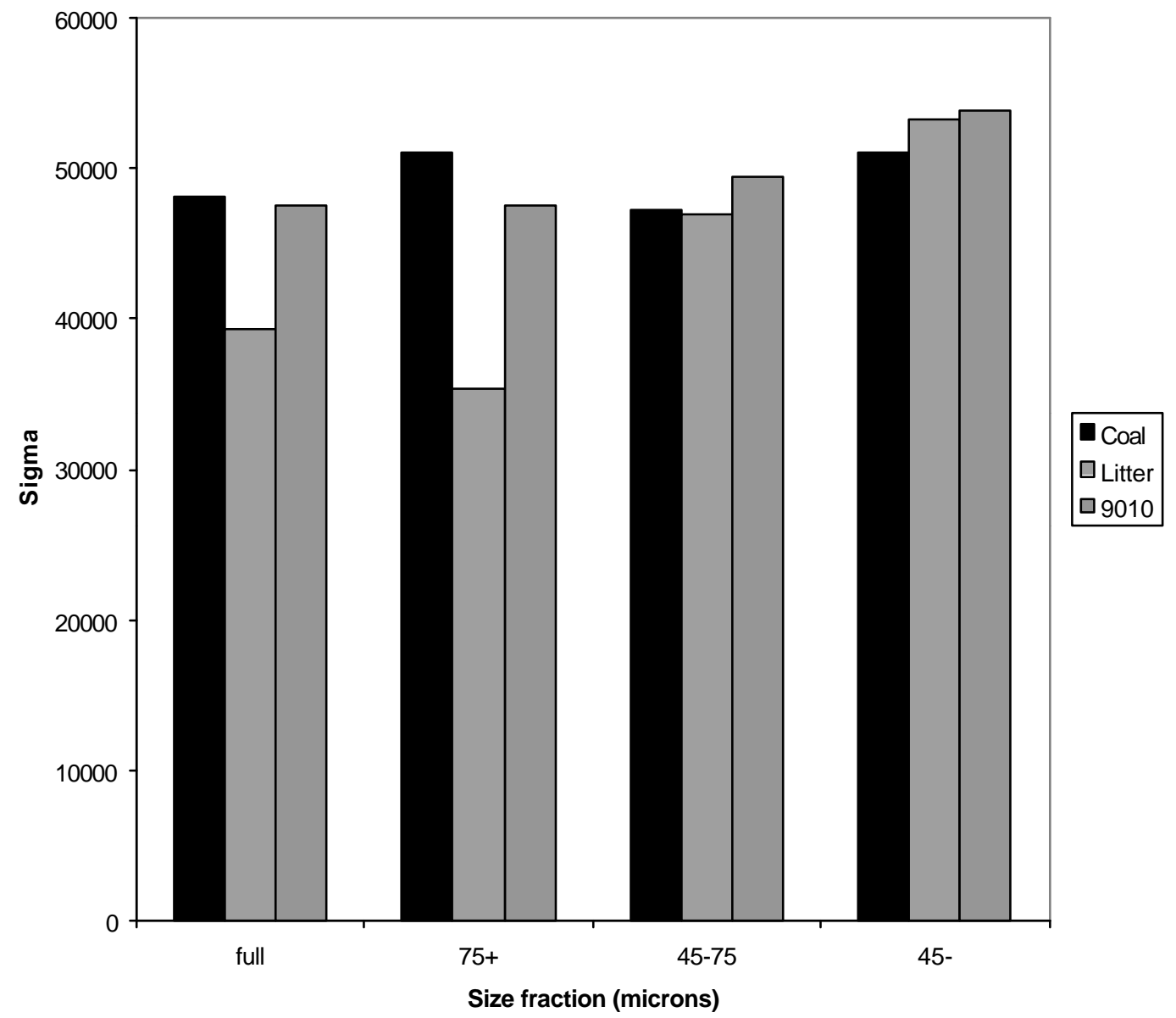

Figure 6: $\sigma$ values for coal, litter, and blend 


\section{Appendix II: Reburn experiments}

Reburn experiments were conducted in the modified Texas A\&M boiler burner facility. The experimental setup was modified with a propane burner to simulate furnace gases, an ammonia injector to produce NO, and injectors to inject reburn fuel. The experimental setup is shown in figure 1. The reburn experiments were conducted over a variety of reburn equivalence ratios with the experimental parameters shown in table 1. The experiments were conducted for coal, litter biomass, 50:50 blend, and 90:10 blend. The results are shown in figure 1 . The results indicate that litter biomass is a considerably better reburn fuel than coal. Litter biomass reduced the amount of NO by $70-80$ percent, while coal reduced the NO emission by 10-40 percent. The behavior of the blended fuels fell between the behavior of the plain coal and the plain litter. It is also noted that a greater reduction is achieved at lower equivalence ratios. 


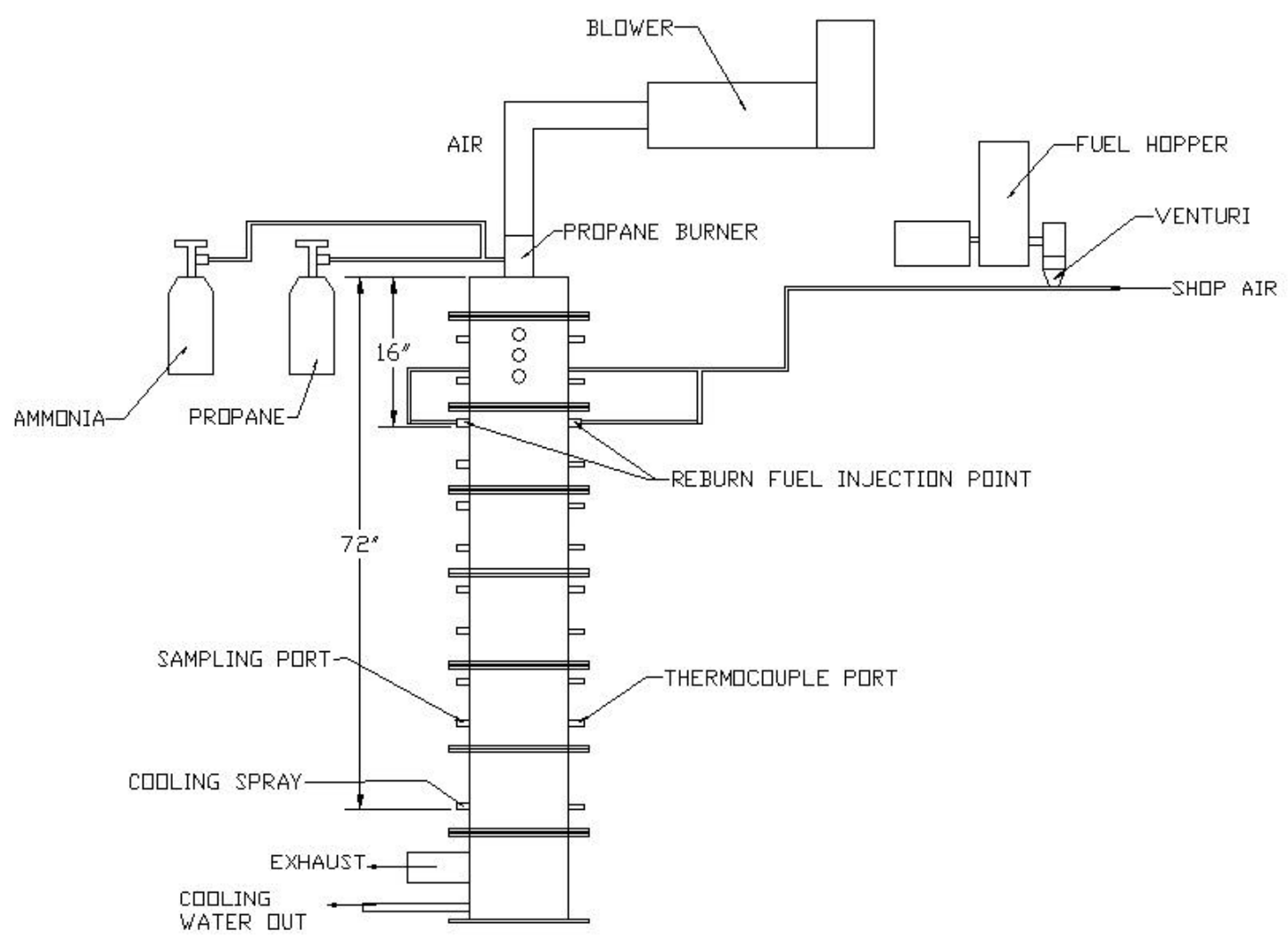

Figure 1, Reburn experimental setup 


\begin{tabular}{|l|l|}
\hline Propane flowrate & $70,000 \mathrm{Btu} / \mathrm{hr}$ \\
\hline Primary airflow rate & $800 \mathrm{SCFH}$ \\
\hline Total burner rating & $100 \mathrm{~kW}$ \\
\hline Reburn Percentage & $30 \%$ \\
\hline Reburn injection velocity & $10-16 \mathrm{~m} / \mathrm{s}$ \\
\hline Primary equivalence ratio & 0.95 \\
\hline Reburn equilivence ratio & $1.00-1.1$ \\
\hline Residence time (cold) & $\sim 4 \mathrm{~s}$ \\
\hline Residence time (hot) & $\sim 1 \mathrm{~s}$ \\
\hline $\begin{array}{l}\text { Initial NO concentration measured at } \\
183 \mathrm{~cm} \text { from burner }\end{array}$ & $600 \mathrm{ppm}$ \\
\hline
\end{tabular}

Table 1: Reburn experimental parameters. 


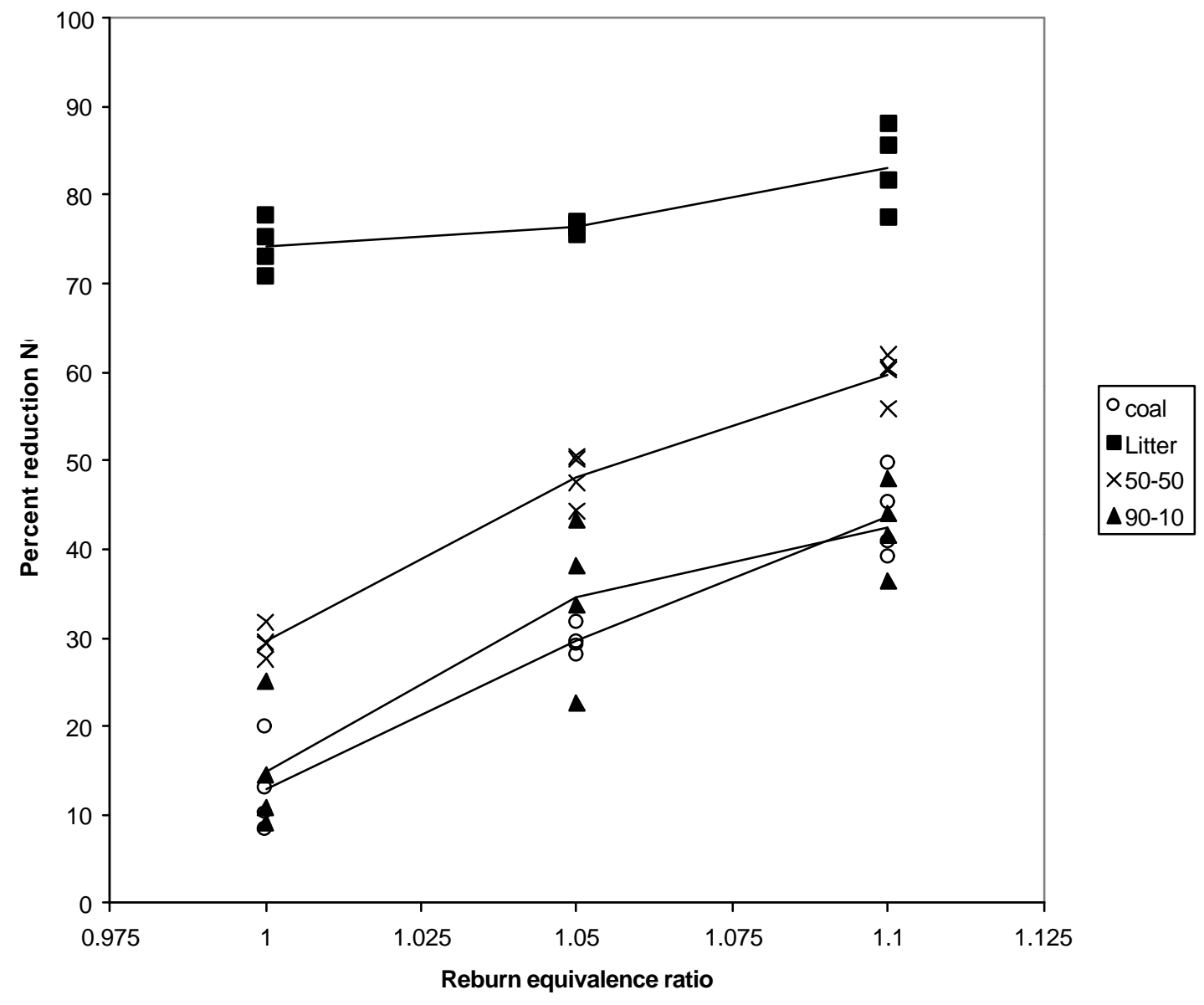

Figure 2: Reburn results. 


\section{Appendix III: Gasifier design}

The fixed bed studies will be done with an updraft gasifier (figure 1), where temperature profiles are measured by thermocouples at five different axial locations in the gasifier. Biomass (or blend) is stored in a hopper and fed from the top of the gasifier by means of two double-slide valves. Air is injected at the bottom of the gasifier. The hot exhaust gas stream passes through the heat recovery unit, which heats the incoming biomass. By the use of a heat recovery unit the supplementary heat (from the hot gases) heats the incoming fuel. The gas sampling is done at two locations (at 18" and 23 1/2" above the base) for gas-chromatographic (GC) analysis. A provision to add excess or secondary air is also available. The gasifier is a cylindrical plain carbon steel tube 20 " high above the grate and 13 1/2" large (internal diameter). A 2 " thick layer of thermal insulating blankets built interior to the reactor between the steel shell and the refractory lining helps in preventing the heat loss from the system. The core of the reactor is a 2" thick refractory material lining, which isolates the combustion zone from the rest of the reactor. The grate, used as an air distributor, is a circular plate (composed of 2" thick of refractory material and 1" thick stainless steel, grade ASTM 368) which has 100.28 " diameter circular holes drilled in it. The zone under the grate is designed to collect the ash, which falls through the grate. The primary air for gasification supplied through this chamber, flows through the grate (so that it is distributed uniformly across the whole section of the gasifier) and into the combustion zone. One inch above the grate, a small tube allows the use of a premixed flame to ignite the bed at the beginning of the process. Temperature profiles along the gasifier axis are measured by thermocouples (ChromelAlumel, 1/4" diameter) placed within a protective tube of 316 stainless steel. The thermocouples are mounted at $141 / 2$ ", 16, 18, $21 \frac{1 / 2}{2}$, and $241 / 2$ " axial location above the base of the gasifier. View ports are provided at two locations above the grate (mounted in opposite pairs, 17" and $231 / 2$ " above the base) and at one location under the grate (5" above the base), for observation of the process. 


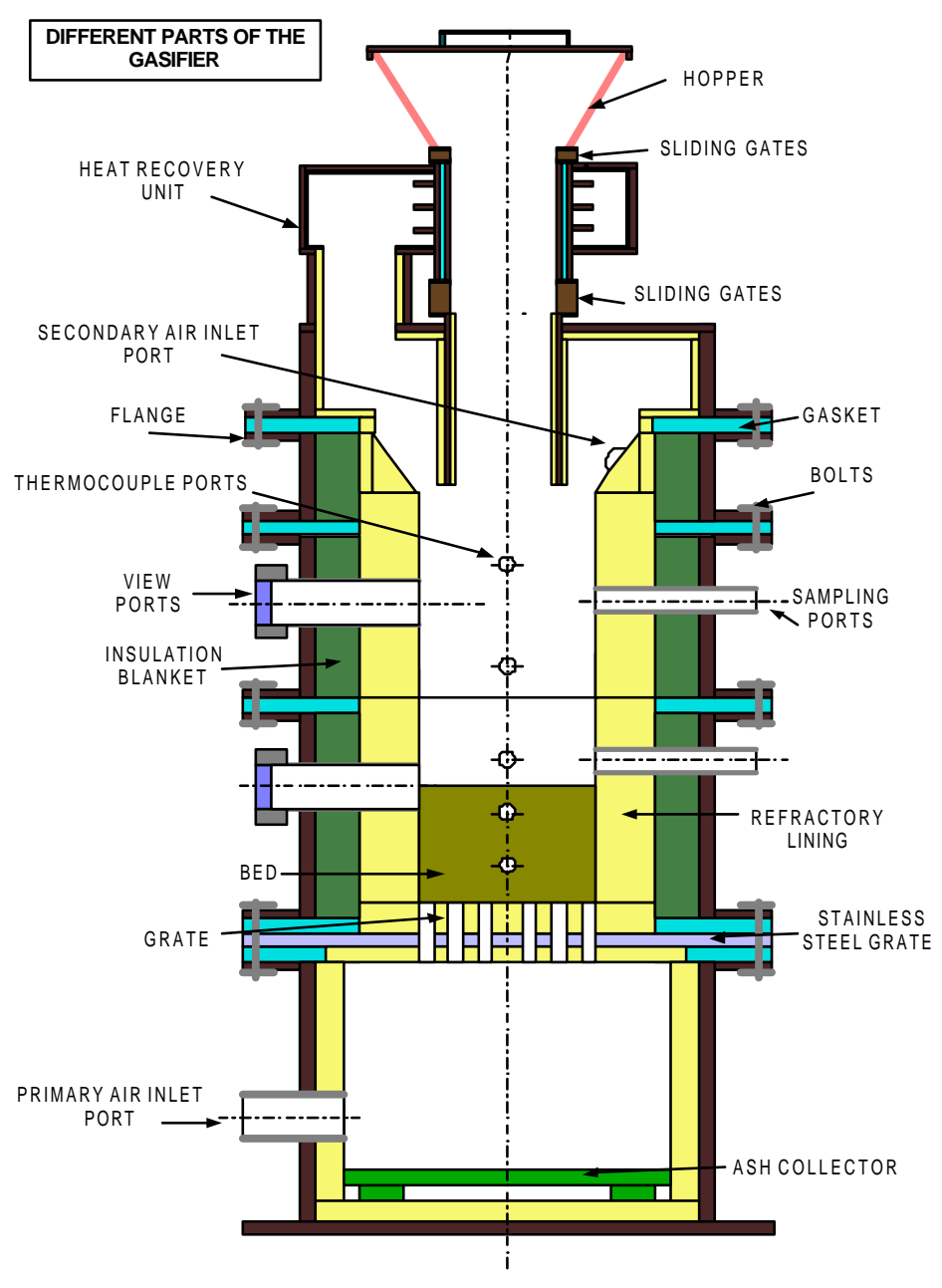

Figure 1, Gasifier 


\section{Appendix IV: PCGC code alterations}

The effects of moisture content on cofiring of pulverized coal and biomass is an important research topic. High moisture content may lower particle temperature and gas phase temperatures thus effecting particle burnout and $\mathrm{NOx}, \mathrm{CO}$ and $\mathrm{CO} 2$ production. Reactions of moisture with carbon monoxide and other species will also affect gas and solid reaction rates and influence the emission of chemical species. In the original PCGC2 code provided by BYU, it is assumed that the moisture in coal particles is released completely and instantaneously before the coal particles enter the burner. In reality, moisture is released gradually with heating. Moisture and volatile matter are released simultaneously, and moisture vaporization is completed earlier than coal devolatilization. An additional mixture fraction can be used to model moisture release, however this may cost unaffordable amounts of CPU time. To investigate moisture effects on combustion with reasonable computational efficiency, we assume that moisture vaporization and coal decomposition occur simultaneously and start and end at the same time. It is assumed that the in particle ratio of moisture mass to mass of daf (dry ash free) undecomposed coal is a constant.

$$
\begin{gathered}
m_{\text {moi }} / m_{\text {coal }}=m_{\text {moi,o }} / m_{\text {coal }, o}=c \\
\text { or, } m_{\text {moi }}=c m_{\text {coal }}
\end{gathered}
$$

Where index o denotes initial values. The moisture vapor production rate and coal decomposition rate has the same ratio. Since no additional mixture fraction is used, moisture is treated the same as coal off gas in regard to chemical composition.

In the last three months, the PCGC2 code was modified to include the moisture model as well as corresponding changes to the energy balance, coal off gas composition, particle density, etc. Test computations were carried out, and the results show that the peak gas phase temperatures and peak $\mathrm{CO}$ concentration increase unreasonably with increasing moisture content in particles. Further analysis found an additional drawback of this moisture model. Since coal off gas composition is assumed constant in PCGC2 and moisture chemical composition is treated the same as coal off gas in the moisture model, more elemental carbon and less elemental hydrogen and oxygen are released during moisture vaporization than reality. The higher the moisture content, the more carbon is released. Higher carbon release causes higher peak gas phase temperatures, which further increase the coal devolatization rate, and in turn results in more carbon release and higher gas temperatures. Due to this drawback, this moisture model has to be abandoned. In the next quarter of the year, phosphorous oxides and NOx emission may be studied using PCGC2 for cofiring of pulverized coal and chicken litter. 